\title{
Prognostic factors of survival in stage IV colorectal cancer with synchronous liver metastasis: Negative effect of the KRAS mutation
}

\author{
MANUEL DÍEZ-ALONSO ${ }^{1}$, FERNANDO MENDOZA-MORENO ${ }^{1}$, LAURA JIMÉNEZ-ÁLVAREZ ${ }^{1}$, \\ OSCAR NUÑEZ ${ }^{2}$, ALMA BLAZQUEZ-MARTÍN ${ }^{1}$, ANA SANCHEZ-GOLLARTE ${ }^{1}$, BELÉN MATÍAS-GARCÍA ${ }^{1}$, \\ RAQUEL MOLINA $^{3}$, ALBERTO SAN-JUAN ${ }^{3}$ and ALBERTO GUTIERREZ-CALVO ${ }^{1}$ \\ ${ }^{1}$ Department of General and Digestive Surgery, Príncipe de Asturias Teaching Hospital, Alcalá de Henares, \\ Madrid 28805; ${ }^{2}$ National Center for Epidemiology, Carlos III Health Institute, Madrid 28029; ${ }^{3}$ Department of Oncology, \\ Príncipe de Asturias Teaching Hospital, Alcalá de Henares, Madrid 28805, Spain
}

Received September 22, 2020; Accepted February 9, 2021

DOI: $10.3892 / \mathrm{mco} .2021 .2255$

\begin{abstract}
The aim of the present study was to identify predictive parameters of survival in patients affected by stage IV colorectal cancer with synchronous and bilateral liver metastases. A retrospective cohort study was performed. Patients diagnosed between January 2013 and December 2018 were included in the present study. Data on the histopathological, clinical and treatment factors (chemotherapy as the first measure or resection of the primary tumor) were collected. The effect of each variable on survival was evaluated using Cox regression analysis. A total of 104 patients were included [43 women (41.3\%) and 61 men (58.7\%); mean age, 63 years]. The long-term survival rate at 36 months was $29 \%$ (median, 25 months). Kaplan-Meier analysis was used to estimate that survival was higher in patients with wild-type KRAS tumors $(42 \%)$ than in patients with mutated KRAS tumors $(9 \%$; $\mathrm{P}=0.001)$. In the multivariate analysis, KRAS mutation (HR, 2.484; 95\% CI, 1.472-4.192), T4 tumors (HR, 1.795; 95\% CI, 1.045-3.084), resection/local treatment of hepatic metastases (HR, 0.447; 95\% CI, 0.222-0.901), Eastern Cooperative Oncology Group performance status (HR, 1.632; 95\% CI, 1.182-2.254), were revealed to have independent predictive value. The type of treatment (chemotherapy
\end{abstract}

Correspondence to: Dr Manuel Díez-Alonso, Department of General and Digestive Surgery, Príncipe de Asturias Teaching Hospital, Carretera de Alcala- Meco S/N, Alcalá de Henares, Madrid 28805, Spain

E-mail: mdiez.hupa@salud.madrid.org

Abbreviations: CRC, colorectal cancer; THM, resection/local treatment of hepatic metastases; ECOG, Eastern Cooperative Oncology Group performance status; PTR, primary tumor resection; WT-KRAS, wild KRAS gene; MT-RAS, mutated KRAS gene; CEA, carcinoembryonic antigen; CA19-9, carbohydrate antigen 19-9; $\mathrm{HR}$, hazard ratio; $95 \% \mathrm{CI}$, confidence interval; OS, overall survival

Key words: colorectal cancer, hepatic metastasis, chemotherapy, KRAS, survival or resection of the primary tumor) did not influence the survival. The results indicated that mutation of the KRAS gene was an important prognostic factor and associated with survival.

\section{Introduction}

Colorectal cancer (CRC) is the third most common malignant tumor and the second leading cause of cancer-associated mortality in Western countries. Currently, 25\% of patients present with liver metastases at the time of diagnosis, and $80 \%$ of cases are bilateral and multiple $(1,2)$. This is a very heterogeneous group of patients. Furthermore, associated comorbidity is often relevant, and thus could determine the most appropriate treatment for each patient. The survival prognosis is poor, and the treatment is usually palliative.

Primary tumor resection (PTR), followed by chemotherapy, has traditionally been considered the first therapeutic option, which aims to decrease the tumor burden and avoid potential complications of the primary tumor. Following intervention, the start of chemotherapy can be delayed or suspended in patients who develop complications after surgery, which occurs in up to $25 \%$ of patients $(3,4)$.

Historically, the median survival for patients with unresectable simultaneous liver metastases was $<8$ months. In the last decade, there has been a substantial improvement in the prognosis, with the median survival currently increased to 24 months (2). This has been possible due to the implantation of second-generation chemotherapeutic agents (5) and monoclonal antibodies against specific targets, such as the epidermal growth factor receptor (EGFR). Furthermore, biological markers, such as the KRAS oncogene, help in the selection of chemotherapeutic agents (6).

The improvement in therapeutic results has motivated the introduction of changes in treatment schemes $(7,8)$. The benefit of surgical resection of the primary tumor on survival and quality of life has been controversial. Due to the fact that it is the degree of liver involvement what determines the survival of these patients (8), surgery treatment on the primary tumor could be avoided in patients with uncomplicated tumors (obstruction, perforation or hemorrhage) $(9,10)$. 
However, the treatment of choice for primary tumors remain debatable. To the best of our knowledge, no randomized controlled trials have yet addressed this clinical question. The results currently published in meta-analyses, clinical series and population-based studies provide unclear conclusions (11-18). The lack of homogeneity of the compared groups and in the control of clinicopathological variables that affect the outcome have limited the conclusions. Therefore, it is necessary to identify prognostic factors that allow to selectively indicate therapeutic strategies.

The present study analyzed the survival of patients with stage IV CRC with bilateral liver metastases. A homogeneous group of patients with good functional status and without multifocal carcinomatosis has been analyzed. The aim was to identify the clinical and histopathological prognostic factors that influenced survival.

\section{Materials and methods}

Retrospective cohort study. Patients diagnosed with stage IV CRC with multiple ( $>3$ metastases), bilateral and synchronous liver metastases, treated between January 2013 and December 2018, were included in the present study. The patients were selected from the data collected in the computerized file of the Coloproctology Unit of Príncipe de Asturias Teaching Hospital, Alcalá de Henares, Spain, which was performed prospectively during this period of time. The present study was approved by the Ethics Committee of the Príncipe de Asturias Teaching Hospital.

The inclusion criteria were as follows: i) Patients aged between 18-75 years; ii) primary tumor with histopathology of colorectal adenocarcinoma, without previous oncological treatment; iii) resectable primary tumor; iv) presence of liver metastases detected by CT or MRI scans, bilateral and multiple, which ensured that the tumor was not surgically resectable; v) absence of peritoneal carcinomatosis, central nervous system or bone metastases; and vi) Eastern Cooperative Oncology Group (ECOG) performance status 0-2. Those patients who presented with locoregional recurrence and those who developed liver metastases during follow-up were excluded.

The diagnosis of colorectal adenocarcinoma was made by histopathological examination of the biopsy obtained via colonoscopy. Levels of carcinoembryonic antigen (CEA) and CA 19-9, and the biochemical parameters, were determined at the time of diagnosis. Thoracic, abdominal and pelvic CT were performed for the staging of distant metastases. Rectal tumors were staged after MRI and endorectal ultrasound. Each patient was discussed by the multidisciplinary team and the metastatic disease was considered to be unresectable. KRAS mutational status (codons 12,13) was assessed in the biopsies of tumor samples obtained by colonoscopy or in the surgically resected tumors, and the results were categorized into two groups: Wild-type KRAS (WT-KRAS) and mutant-type KRAS (MT-KRAS).

Treatment. Patients with asymptomatic tumors or stenosing tumors, but in whom a stent was implanted previously or a derivative colostomy was performed, were initially treated with chemotherapy. Cisplatin/irinotecan-based therapy (FOLFOX/FOLFIRI) and bevacizumab or anti-epidermal growth factor receptor (anti-EGFR) antibodies (cetuximab or panitumab) were administered based on the KRAS mutation status in the tumor biopsy. Next, six cycles of chemotherapy were programmed according with the cited scheme. Once treatment was finished, the response of primary tumor and metastases were evaluated via a CT scan. According to RECIST criteria (Version 1.1) (19). In the case of stability or partial response, PTR was performed. After PTR, resection (segmental/lobar hepatectomy) or local non-surgical treatment (radiofrequency, microwave ablation) of hepatic metastases was evaluated.

Patients with tumors where it was not possible to pass the colonoscopy beyond the primary tumor and therefore could not implant a stent, were treated with PTR as the first measure, followed by chemotherapy. Patients with asymptomatic tumors were also included in this group, in which the patient and the multidisciplinary medical team decided this measure. After surgery, chemotherapy and follow-up were scheduled as per the previous group.

Statistical analysis. Variables were collected in a spreadsheet of Microsoft Excel 2019 (v.19). Statistical analysis was performed by SPSS program (v.23) (IBM, Armonk). The present study first described survival time in the CRC cohort of patients. Follow-up was defined as the time between diagnosis and death, or the last time of medical appointment. Overall survival $(\mathrm{OS}) \leq 3$ years after diagnosis and median survival were estimated (with $95 \%$ CI) with each variable by using the Kaplan-Meir test. Survival curves were compared by log-rank test. Next, the present study focused on the association between the KRAS mutation status and patient survival. The distribution of patient and tumor characteristics between groups of KRAS mutations was compared using the Kruskal-Wallis test. Finally, the effect of the KRAS mutation on survival adjusted for these characteristics was evaluated using a Cox proportional hazard regression. $\mathrm{P}<0.05$ was considered to indicate statistically significant.

\section{Results}

Patient characteristics. A total of 104 patients were included in the present study, 43 women (41.3\%) and 61 men (58.7\%), with a mean age of $63 \pm 10$ years. The clinicopathological characteristics are presented in Table I.

Of these patients, $60(57.7 \%)$ were treated with chemotherapy as the first measure, and 44 (42.3\%) with RTP as first measure. In total,PTR was performed on 74 patients $(71.1 \%)$ and $30(28.9 \%)$ were treated with chemotherapy only. The location of the primary tumor was in the rectum in 36 patients $(34.6 \%)$, in the left colon in 48 patients $(46.2 \%)$ and in the right colon in 20 patients $(19.2 \%)$. A mutation in the KRAS gene was detected in 51 patients $(49 \%)$. In 38 cases $(36.5 \%)$, the ECOG Index was 0 . The Charlson Comorbidity Index was $>8$ in $51(49 \%)$ patients. Resection/local treatment of liver metastases (THM) could be performed in 28 patients $(26.9 \%)$.

Patients initially treated with chemotherapy. In this group, which was composed of 60 patients, response/stabilization of metastatic disease was recorded in 38 patients $(63.3 \%)$ and progression/appearance of new metastases in 22 (36.7\%). The 38 patients who showed a response to chemotherapy 
Table I. Patient and tumor characteristics and survival estimates at 36 months after diagnosis.

\begin{tabular}{|c|c|c|c|c|c|c|}
\hline Characteristic & $\begin{array}{l}\text { Patients, } \\
\text { n (\%) }\end{array}$ & $\begin{array}{c}\text { Cumulative } \\
\text { survival at } \\
36 \text { months }\end{array}$ & $\begin{array}{c}\text { Median } \\
\text { survival } \\
\text { time, months }\end{array}$ & P-value & HR & $95 \% \mathrm{CI}$ \\
\hline Sex & & & & 0.005 & & \\
\hline Male & $61(58.7)$ & 34 & 28 & & 1 & \\
\hline Female & $43(41.3)$ & 9 & 21 & & 1.96 & $1.21-3.20$ \\
\hline Age, years & & & & 0.190 & & \\
\hline$<60$ & $34(32.7)$ & 29 & 27 & & 1 & \\
\hline$\geq 60$ & $70(67.3)$ & 21 & 23 & & 1.41 & $0.82-2.45$ \\
\hline ECOG & & & & 0.001 & & \\
\hline 0 & $38(36.5)$ & 42 & 35 & & 1 & \\
\hline $1-2$ & $66(63.5)$ & 16 & 21 & & 2.77 & $1.5-5.10$ \\
\hline Localization & & & & 0.025 & & \\
\hline Right colon & $20(19.2)$ & 13 & 17 & & 1.96 & $1.03-3.72$ \\
\hline Left colon & $48(46.2)$ & 28 & 25 & & 0.90 & $0.51-1.59$ \\
\hline Rectum & $36(34.6)$ & 24 & 27 & & 1 & 1 \\
\hline Charlson index & & & & 0.370 & & \\
\hline$\leq 8$ & $53(51)$ & 24 & 27 & & 1 & \\
\hline$>8$ & $51(49)$ & 23 & 21 & & 1.41 & $0.82-2.41$ \\
\hline T stage & & & & 0.030 & & \\
\hline $\mathrm{T} 2-3$ & $70(67.3)$ & 27 & 28 & & 1 & \\
\hline $\mathrm{T} 4$ & 34 (32.7) & 16 & 20 & & 1.7 & $1.03-2.90$ \\
\hline $\mathrm{N}$ stage & & & & 0.470 & & \\
\hline No & $19(18.3)$ & 29 & 27 & & 1 & \\
\hline $\mathrm{N} 1-2$ & $85(81.7)$ & 22 & 24 & & 1.25 & $0.65-2.40$ \\
\hline Therapeutic program & & & & 0.510 & & \\
\hline Surgery first & $44(42.3)$ & 19 & 23 & & 1 & \\
\hline Chemotherapy first & $60(57.7)$ & 29 & 25 & & 0.85 & $0.52-1.38$ \\
\hline Resection primary tumor & & & & 0.420 & & \\
\hline Yes & $74(71.2)$ & 25 & 25 & & 1 & \\
\hline No & $30(28.8)$ & 21 & 21 & & 1.23 & $0.72-2.09$ \\
\hline Lung metastases & & & & 0.990 & & \\
\hline Absent & $85(81.7)$ & 22 & 24 & & 1 & \\
\hline Present & $19(18.3)$ & 27 & 26 & & 0.99 & $0.54-1.83$ \\
\hline $\begin{array}{l}\text { Resection/local treatment } \\
\text { hepatic metastases }\end{array}$ & & & & 0.001 & & \\
\hline Yes & $28(29.9)$ & 46 & 35 & & 0.32 & $0.15-0.65$ \\
\hline No & $76(73.1)$ & 17 & 21 & & 1 & \\
\hline KRAS status & & & & 0.001 & & \\
\hline Native & $53(51)$ & 42 & 30 & & 1 & \\
\hline Mutated & $51(49)$ & 9 & 21 & & 2.33 & 1.39-3.9 \\
\hline Grade of differentiation & & & & 0.290 & & \\
\hline Poorly differentiated & $19(19.3)$ & 23 & 17 & & 1 & \\
\hline Well-moderately differentiated & $85(81.7)$ & 24 & 23 & & 1.39 & $0.74-2.60$ \\
\hline Histologic type & & & & 0.190 & & \\
\hline Classical adenocarcinoma & $96(92.3)$ & 24 & 25 & & 1 & \\
\hline Mucinous & $6 \quad(7.7)$ & 19 & 17 & & 0.55 & $0.22-1.39$ \\
\hline $\mathrm{CEA}, \mathrm{ng} / \mathrm{ml}$ & & & & 0.110 & & \\
\hline$\leq 10$ & $30(28.8)$ & 36 & 30 & & 1 & \\
\hline$>10$ & $74(71.2)$ & 19 & 23 & & 1.59 & $0.86-2.93$ \\
\hline
\end{tabular}


Table I. Continued.

\begin{tabular}{|c|c|c|c|c|c|c|}
\hline Characteristic & $\begin{array}{c}\text { Patients, } \\
\mathrm{n}(\%)\end{array}$ & $\begin{array}{c}\text { Cumulative } \\
\text { survival at } \\
36 \text { months }\end{array}$ & $\begin{array}{c}\text { Median } \\
\text { survival } \\
\text { time, months }\end{array}$ & P-value & HR & $95 \% \mathrm{CI}$ \\
\hline CA19-9, U/ml & & & & 0.030 & & \\
\hline$\leq 37$ & $48(46.2)$ & 35 & 30 & & 1 & \\
\hline$>37$ & $56(53.8)$ & 15 & 21 & & 1.67 & $1.02-2.30$ \\
\hline GOT, U/1 & & & & 0.053 & & \\
\hline$\leq 34$ & 63 (60.6) & 28 & 28 & & 1 & \\
\hline$>34$ & $35(39.4)$ & 18 & 21 & & 1.59 & $0.97-2.60$ \\
\hline $\mathrm{AF}, \mathrm{U} / \mathrm{l}$ & & & & 0.120 & & \\
\hline$\leq 120$ & 55 (52.9) & 30 & 27 & & 1 & \\
\hline$>120$ & 49 (46.2) & 17 & 24 & & 1.12 & $0.88-2.36$ \\
\hline
\end{tabular}

A $\chi^{2}$ test was used to calculate the P-values. HR, hazard ratio; 95\% CI, confidence intervals; CEA, carcinoembryonicantigen; CA19.9, carbohydrate antigen 19-9; GOT, glutamic oxalacetic transaminase; AF, alkaline phosphatase; ECOG, Eastern Cooperative Oncology Group performance status.

were evaluated to perform PTR, and 33 were finally operated on. Of these, five patients were not operated on; one due to complete response of the primary tumor; three for serious comorbidities associated with their disease (pulmonary hypertension, ischemic heart disease and progressive deterioration of functional status); and one of them for presenting with serious complications to the chemotherapy (ischemic stroke) (in this patient, a colostomy was subsequently performed due to intestinal obstruction). Among the 33 patients that received surgery, 5 presented with unresectable local disease at the time of the intervention.

The 22 patients in whom progression was recorded were treated with new lines of chemotherapy. During follow-up, 8 of them developed intestinal obstruction, 5 of them had a colostomy performed, 1 had a stent implanted and 2 had resection of the primary tumor performed.

Overall, in this group of patients, PTR was performed in 30 patients and another 30 were treated with chemotherapy alone. A total of 9 patients (30\%) developed morbidity to some extent following surgery: Two cases of intra-abdominal infection and 7 of wound infection. No postoperative death was observed.

THM was subsequently performed in 15 patients $(25 \%)$; 3 received lobectomy and radiofrequency; 4 received segmental resection; 6 received radiofrequency and 2 received chemoembolization and thermoablation.

Patients initially treated by PTR. Following PTR, 14 of the 37 patients in this group (37\%) developed some complication. Of these, one died from intra-abdominal infection and peritonitis; 6 presented with anastomotic fistula; one with evisceration; one with prolonged ileus and one with pneumonia; and six presented with wound infection. In addition, 3 patients were unable to receive the chemotherapy initially planned; one had died after the intervention and two developed serious sequelae of post-surgical complications. In two other patients, the start of treatment was delayed $>3$ months after surgery due to surgical complications. THM was subsequently performed in 13 patients (35\%);
2 received lobectomy, 2 received segmentectomy, 7 received radiofrequency and 2 received chemoembolization.

Long-term survival. Survival, at 36 and 60 months after diagnosis, was 29 and 8\%, respectively (median, 25 months) (95\% CI, 21-28). The results of the univariate analysis of survival, performed at 36 months after diagnosis by patients and tumor characteristics, is presented in Table I. Survival was higher in patients with WT-KRAS tumors (42 vs. 9\%; median, 30 vs. 21 months; $\mathrm{P}=0.001$ ) (Fig. 1), patients in whom THM could be performed (46 vs. 17\%; median, 35 vs. 21 months; $\mathrm{P}=0.001$ ), T2-3 tumors ( 27 vs. $16 \%$; median, 28 vs. 20 months; $\mathrm{P}=0.03$ ) and in $\mathrm{ECOG}$ 0 patients (42 vs. $16 \%$; median, 35 vs. 21 months; $\mathrm{P}=0.001$ ).

The risk of dying was significantly higher in women (HR, 1.96), patients with ECOG Index 1-2 (HR, 2.77), tumors of the right colon (HR, 1.96), T4 tumors (HR, 1.7), MT-KRAS tumors (HR, 2.33) and patients with CA 19-9 levels $>37 \mathrm{ng} / \mathrm{ml}$ (HR, 1.67). The risk of dying was lower when THM was performed (HR, 0.32).

Survival was not influenced by the type of treatment (surgery versus chemotherapy). Survival in the group of patients initially treated with chemotherapy was $29 \%$ (median, 25 months), and was 19\% among those treated with PTR as first step (median, 23 months) $(\mathrm{P}=0.51)$. There were also no differences in survival regarding the action on the primary tumor; when the tumor was resected, survival was $25 \%$ (median, 25) vs. $21 \%$ among those treated with chemotherapy only (median, 21) $(\mathrm{P}=0.42)$.

Variation of survival results is observed depending on the KRAS status. When PTR was performed, survival was 13\% (median, 23 months) in MT-KRAS tumors, compared with $42 \%$ (median, 31 months) in WT-KRAS tumors $(\mathrm{P}=0.032)$ (Fig. 2). Among those treated with chemotherapy only, survival was $0 \%$ (median, 15 months) in MT-KRAS tumors and 44\% (median, 28 months) in WT-KRAS tumors ( $\mathrm{P}=0.002)$ (Fig. 3).

Mutation frequency in KRAS was analyzed with regard to clinical and histopathological factors (Table II). The presence 
Table II. KRAS mutation status according to patient and tumor characteristics.

\begin{tabular}{|c|c|c|c|c|}
\hline Characteristic & Total, $\mathrm{n}$ & WT KRAS, n (\%; n=53) & MT KRAS, n (\%; n=51) & P-value \\
\hline Sex & & & & 0.015 \\
\hline Male & 61 & $37(60.6)$ & $24(39.4)$ & \\
\hline Female & 43 & $16(37.2)$ & $27(62.8)$ & \\
\hline Age, years & & & & 0.180 \\
\hline$<60$ & 34 & $20(58.8)$ & $14(41.2)$ & \\
\hline$\geq 60$ & 70 & $33(47.2)$ & $37(52.8)$ & \\
\hline ECOG & & & & 0.069 \\
\hline 0 & 38 & $24(63.2)$ & $14(36.8)$ & \\
\hline $1-2$ & 66 & $29(43.9)$ & $37(50.1)$ & \\
\hline Tumor localization & & & & 0.001 \\
\hline Right colon & 20 & $3(15)$ & $17(85)$ & \\
\hline Left colon & 48 & $27(56.2)$ & $21(43.8)$ & \\
\hline Rectum & 36 & $23(63.9)$ & $13(36.1)$ & \\
\hline Charlson index & & & & 0.550 \\
\hline$\leq 8$ & 53 & $29(54.7)$ & $24(45.3)$ & \\
\hline$>8$ & 51 & $24(47)$ & $27(53)$ & \\
\hline T stage & & & & 0.310 \\
\hline $\mathrm{T} 2-3$ & 70 & $34(48.6)$ & $36(51.4)$ & \\
\hline $\mathrm{T} 4$ & 34 & $19(55.9)$ & $15(44.1)$ & \\
\hline $\mathrm{N}$ stage & & & & 0.270 \\
\hline $\mathrm{N}$ negative & 19 & $8(42.1)$ & $11(57.9)$ & \\
\hline N positive & 85 & $45(53)$ & $40(47)$ & \\
\hline Treatment program & & & & 0.020 \\
\hline Surgery first & 60 & $36(60)$ & $24(40)$ & \\
\hline Chemotherapy first & 44 & $17(38.6)$ & $27(61.4)$ & \\
\hline Primary tumor resection & & & & 0.460 \\
\hline Yes & 74 & $37(50)$ & $37(50)$ & \\
\hline No & 30 & $16(53.3)$ & $14(46.7)$ & \\
\hline Lung metastases & & & & 0.530 \\
\hline Absent & 85 & $43(50.6)$ & $42(49.4)$ & \\
\hline Present & 19 & $10(52.6)$ & $9(47.4)$ & \\
\hline Resection/local treatment hepatic metastases & & & & 0.016 \\
\hline No & 76 & $35(46)$ & $41(54)$ & \\
\hline Yes & 28 & $19(67.9)$ & $9(32.1)$ & \\
\hline Grade of differentiation & & & & 0.460 \\
\hline Well-moderately differentiated & 85 & $44(52.8)$ & $41(48.2)$ & \\
\hline Poorly differentiated & 19 & $9(47.3)$ & $10(52.7)$ & \\
\hline $\mathrm{CEA}, \mathrm{ng} / \mathrm{ml}$ & & & & 0.300 \\
\hline$\leq 10$ & 30 & $17(56.6)$ & $13(43.4)$ & \\
\hline$>10$ & 74 & $36(48.7)$ & $38(51.3)$ & \\
\hline CA19-9, U/1 & & & & 0.009 \\
\hline$\leq 37$ & 48 & $31(64.5)$ & $17(35.5)$ & \\
\hline$>37$ & 56 & $22(39.3)$ & $34(60.7)$ & \\
\hline GOT, U/1 & & & & 0.280 \\
\hline$<34$ & 63 & $34(54)$ & $29(46)$ & \\
\hline$>34$ & 41 & $19(46.3)$ & $22(53.7)$ & \\
\hline AF, U/1 & & & & 0.420 \\
\hline$\leq 120$ & 55 & $29(52.7)$ & $26(47.3)$ & \\
\hline$>120$ & 49 & $24(49)$ & $25(51)$ & \\
\hline
\end{tabular}

A $\chi^{2}$ test was used to calculate the P-values. CEA, carcinoembryonicantigen; CA19.9, carbohydrate antigen 19-9; GOT, glutamic oxalacetic transaminase; ECOG, Eastern Cooperative Oncology Group performance status; AF, alkaline phosphatase. 
Table III. Predictive factors of survival analyzed using Cox's proportional hazards model.

$95.0 \%$ confidence interval

\begin{tabular}{lcccc}
\cline { 3 - 4 } Factor & P-value & Hazard ratio & Inferior & Superior \\
\hline KRAS mutation & 0.001 & 2.484 & 1.472 & 4.192 \\
Resection/local treatment of hepatic metastases & 0.024 & 0.447 & 0.222 & 0.901 \\
T4 stage & 0.034 & 1.795 & 1.045 & 3.084 \\
ECOG Performance 1-2 & 0.003 & 1.632 & 1.182 & 2.254
\end{tabular}

ECOG, Eastern Cooperative Oncology Group performance status.

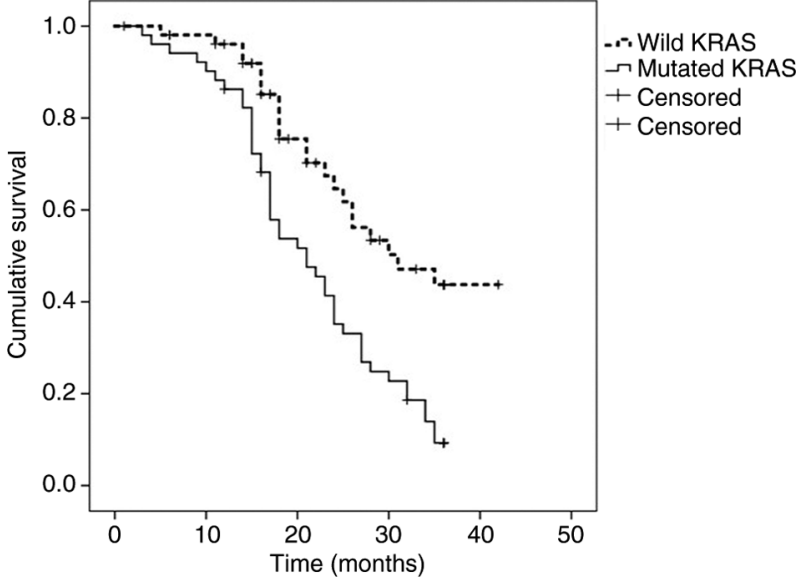

Figure 1. Kaplan-Meier survival estimates at 36 months for the entire cohort according to KRAS mutation status.

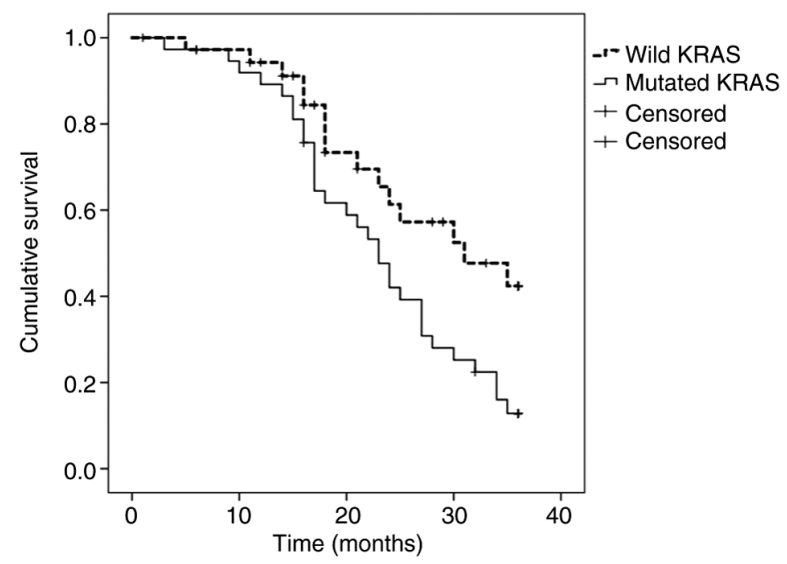

Figure 2. Kaplan-Meier survival estimates according to KRAS mutation status when primary tumor resection was performed.

of the mutation was more frequent in tumors of the right colon $(\mathrm{P}=0.001)$, in women $(\mathrm{P}=0.01)$ and in patients in whom THM could be performed $(\mathrm{P}=0.016)$.

In the multiple regression analysis (Table III), the factors that showed an independent predictive value were: The presence of the KRAS mutation (HR, 2.484; 95\% CI, 1.472-4.192), T4 tumors (HR, 1.795; 95\% CI, 1.045-3.084), THM (HR, 0.447; 95\% CI, 0.222-0.901) and ECOG 1-2 (HR, 1.632; $95 \%$ CI, 1.182-2.254).

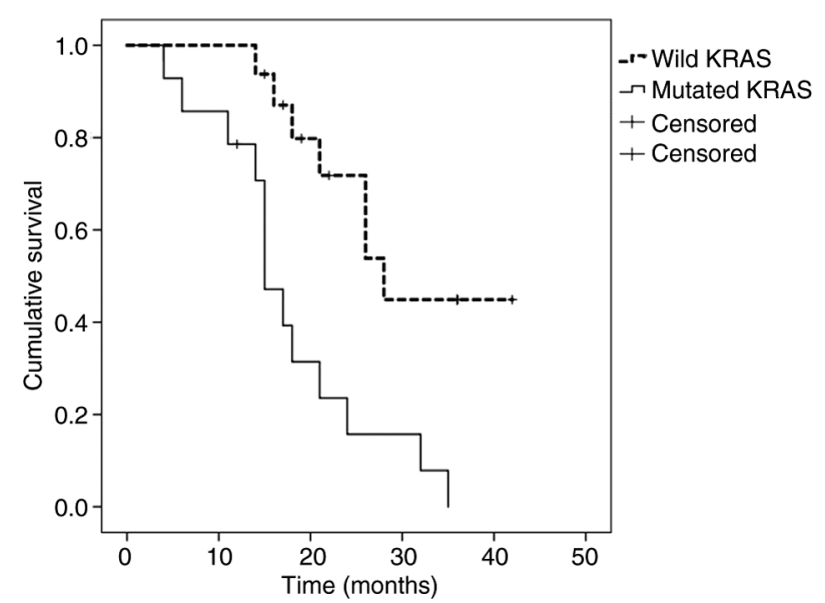

Figure 3. Kaplan-Meier survival estimates according to KRAS mutation status among patients treated with chemotherapy only.

\section{Discussion}

There is no consensus on the indication of PTR in patients with stage IV CRC with bilateral and synchronous liver metastasis. This controversy comes from the absence of reliable prognostic factors that allow to selectively indicate therapeutic strategies $(3,13)$. In the present study, the two types of treatment issued, chemotherapy or PTR, offered similar influence on survival.

The present study indicated that KRAS mutation status, T4 stage, THM performance and ECOG Index, have independent predictive values on the survival of patients with stage IV CRC. Among them, the KRAS mutation exhibited greater predictive importance. Patients with MT-RAS tumors had a 2.48-times higher risk of dying than patients with WT-RAS tumors, and the OS at 36 months was lower (9 vs. 42\%) $(\mathrm{P}=0.001)$. However, the most important data in our study was the finding that the results of the treatment varied depending on the KRAS status. When RPT was performed, the survival at 36 months was $13 \%$ in MT-KRAS tumors versus $42 \%$ in WT KRAS tumors $(\mathrm{P}=0.032)$. Likewise, among those treated with chemotherapy only, the 36-month survival was $0 \%$ in MT-RAS tumors and 44\% in WT-KRAS tumors $(\mathrm{P}=0.002)$.

KRAS is a key component of the EGFR signal transduction pathway, affecting the proliferation and angiogenesis of the tumor cells. KRAS mutations are present in $\sim 40 \%$ of CRC cases. A mutated KRAS gene is constitutively activated, 
enabling the downstream effects of the EGFR signaling pathway independent of EGFR activation by the ligand, thus leading to uninterrupted proliferation (17). Identification of KRAS status is decisive to indicate EGFR-targeted agents (18).

Previous publications have also reported that the presence of the KRAS mutation is significantly associated with decreased survival in stage IV CRC patients (20-22). The results of those studies indicate that the worst prognosis for patients with MT-KRAS tumors was independent of chemotherapy treatment and was due to more aggressive tumor behavior.

In the present study, the KRAS mutation was more frequent in women and in tumors located in the right colon. These findings are in line with data published in previous studies. In addition, some studies have found that survival in patients with tumors of the right colon is lower than that observed in patients with tumors of the left colon and rectum, and this difference is particularly significant in patients with stage IV disease $(23,24)$. It is thought that the worst progression of proximal tumors could be attributed in part to the higher frequency with which genetic alterations, such as BRAF and KRAS mutations, microsatellite instability and $\mathrm{CpG}$ island methylator phenotype, are detected $(25,26)$.

The choice of treatment in patients with stage IV CRC with bilateral and synchronous liver metastasis must be individualized. It seems appropriate to indicate PTR as the first therapeutic measure for patients with symptomatic tumors (obstruction, perforation or bleeding). In other cases, the choice must be based on other aspects. Tumor burden, comorbidities and patient functional status are objective and useful parameters. However, the data from the present study indicate that the genetic profile of the tumor must also be taken into account, particularly the mutation status of the KRAS gene. The negative influence on the prognostic of survival that MT-RAS has demonstrated, may have a practical application to advise on the survival that can be expected in each patient, and thus it may be an aid to provide a specific treatment. Our data indicate that KRAS status may help to differentiate subgroups of patients with different prognostic of survival. This information would be useful to adjust the therapeutic effort in each patient. Hypothetically, traumatic RPT surgery could be avoided in asymptomatic MT-RAS tumors, since this act will not provide an improvement in survival.

The main limitations of the present study are the small sample size and the retrospective design. We know that it is impossible to obtain firm conclusions with such a reduced number of patients, although the homogeneity of the population studied is in its favor. But we think that the results obtained are clinically significant. If MT-KRAS has shown a strong predictive effect with a reduced sample of patients, it is indicative of the real value that it owns as prognostic factor of survival. However, it is necessary to perform prospective studies with a higher number of patients.

The results of the present study indicate that the mutational status of the KRAS gene is connected with survival and may be a useful prognostic parameter in patients with stage IV $\mathrm{CRC}$ with multiple and synchronous liver metastases.

\section{Acknowledgements}

Not applicable.

\section{Funding}

No funding was received.

\section{Availability of data and materials}

The datasets used and/or analyzed during the current study are available from the corresponding author on reasonable request.

\section{Authors' contributions}

MDA and FMM were involved in study concept and design. MDA, FMM, LJA and ON have contributed to the analysis of data, and the preparation and drafting of the manuscript. ABM, ASG, ASJ, BMG, RM and AGC made substantial contributions to acquisition of data and database compilation. MDA and FMM were responsible for assessing the authenticity of all raw data. All authors read and approved the final manuscript.

\section{Ethics approval and consent to participate}

The present study was approved by the Ethics and Clinical Trials Committee of the Príncipe de Asturias Teaching Hospital (Madrid, Spain).

\section{Patient consent for publication}

Not applicable.

\section{Competing interests}

The authors declare that they have no competing interests.

\section{References}

1. Leporrier J, Maurel J, Chiche L, Bara S, Segol P and Launoy G: A population-based study of the incidence, management and prognosis of hepatic metastases from colorectal cáncer. Br J Surg 93: 464-474, 2006.

2. Krell RW and D'Angelica M: Treatment sequencing for simultaneous colorectal liver metastases. J Surg Oncol 119: 583-593, 2019.

3. Cirocchi R, Trastulli S, Abraha I, Vettoretto N, Boselli C, Montedori A, Parisi A, Noya G and Platell C: Nonresection versus resection for asymptomatic primary tumour in patients with unresectable stage IV colorectal cáncer. Cochrane Database Syst Rev 8: CD008997, 2012.

4. Aslam MI, Kelkar A, Sharpe D and Jameson JS: Ten years' experience of managing the primary tumours in patients with stage IV colorectal cancers. Int J Surg 8: 305-313, 2010.

5. Sanoff HK, Sargent DJ, Campbell ME, Morton RF, Fuchs CS, Ramanathan RK, Williamson SK, Findlay BP, Pitot HC and Goldberg RM: Five-year data and prognostic factor analysis of oxaliplatin and irinotecan combinations for advanced colorectal cáncer: N9741. J Clin Oncol 26: 5721-5727, 2008.

6. Van Cutsem E, Köhne CH, Hitre E, Zaluski J, Chang Chien CR, Makhson A, D'Haens G, Pintér T, Lim R, Bodoky G, et al: Cetuximab and chemotherapy as initialtreatment for metastatic colorectal cáncer. N Engl J Med 360: 1408-1417, 2009.

7. Ahmed S, Shahid RK, Leis A, Haider K, Kanthan S, Reeder B and Pahwa P: Shoudnoncurative resection of the primary tumor be performed in patients with stage IV colorectal cáncer? A systematic review and meta-analysis. Curr Oncol 20: e420-441, 2013.

8. Stillwell AP, Buettner PG and Ho YH: Meta-analysis of survival of patients with stage IV colorectal cáncer managed with surgical resección versus chemotherapy alone. World J Surg 34: 797-807, 2010. 
9. Van Cutsem E, Cervantes A, Adam R, Sobrero A, Van Krieken JH, Aderka D, Aranda Aguilar E, Bardelli A, Benson A, Bodoky G, et al: ESMO consensus guidelines for the management of patients with metastatic colorectal cáncer. Ann Oncol 27: 1386-1422, 2016.

10. Messersmith WA: NCCN guidelines updates: Management of metastatic colorectal cancer. J NatlCompr Cancer Netw 17: 599-601, 2019.

11. Alawadi Z, Phatak UR, Hu CY, Bailey CE, You YN, Kao LS, Massarweh NN, Feig BW, Rodriguez-Bigas MA, Skibber JM and Chang GJ: Comparative effectiveness of primary tumor resection in patients with stage IV colon cáncer. Cancer 123: 1124-1133, 2017.

12. Lee K, Ou Y, Hu WH, Liu CC and Chen HH: Meta-analysis of outcomes of patients with stage IV colorectal cáncer managed with chemotherapy/radiochemotherapy with and without primary tumor resection. Onco Targets Ther 9: 7059-7069, 2016.

13. Hu CY, Bailey CE, You YN, Skibber JM, Rodriguez-Bigas MA, Feig BW and Chang GJ: Time trend analysis of primary tumor resection for stage IV colorectal cáncer: Less surgery, improved survival. JAMA Surg 150: 245-251, 2015.

14. Tarantino I, Warschkow R and Güller U: Palliative primary tumor resection in patients with metastatic colorectal cancer: For whom and when? Ann Surg 265: e59-e60, 2016.

15. Mehta HB, Vargas GM, Adhikari D, Dimou F and Riall TS: Comparative effectiveness of chemotherapy vs resection of the primary tumour as the initial treatment in older patients with stage IV colorectal cáncer. Colorectal Dis 19: O210-O218, 2017.

16. Tominaga T, Nonaka T, Shiraisi T, Hamada K, Noda K, Takeshita $H$, Maruyama K, Fukuoka $H$, Wada $H$, Hashimoto $\mathrm{S}$, et al: Factors related to short-term outcomes and delayed systemic treatment following primary tumor resection for asymptomatic stage IV colorectal cáncer. Int J Colorectal Dis 35: 837-846, 2020.

17. Rehman A, Jones RP and Poston G: Prognostic and predictive markers in liver limited stage IV colorectal cáncer. Eur J Surg Oncol 45: 2251-2256, 2019.

18. Yarom N, Gresham G, Boame N andJonker D: KRAS status as a predictor of chemotherapy activity in patients with metastatic colorectal cancer. Clin Colorectal Cancer 18: e309-e315, 2019.

19. Eisenhauer EA, Therasse P, Bogaerts J, Schwartz LH, Sargent D, Ford R, Dancey J, Arbuck S, Gwyther S, Mooney M, et al: New response evaluation criteria in solid tumours: Revised RECIST guideline (version 1.1). Eur J Cancer 45: 228-247, 2009.
20. Yeom SS, Lee SY, Kwak HD, Kim CH, Kim YJ and Kim HR: The outcome of primary tumor resection in the unresectable stage IV colorectal cáncer patients who received the bevacizumabcontaining chemotherapy. Medicine (Baltimore) 99: e19258, 2020.

21. Andreyev HJ, Norman AR, Cunningham D, Oates J, Dix BR, Iacopetta BJ, Young J, Walsh T, Ward R, Hawkins N, et al: Kirsten ras mutations in patients with colorectal cáncer: The RASCAL II study. Br J Cancer 85: 692-696, 2001.

22. Phipps AI, Buchanan DD, Makar KW, Win AK, Baron JA, Lindor NM, Potter JD and Newcomb PA: KRAS-mutation status in relation to colorectal cancer survival: The joint impact of correlated tumour markers. Br J Cancer 108: 1757-1764, 2013.

23. Tapia Rico G, Price T, Tebbutt N, Hardinghamm J, Lee C, Buizen L, Wilson K, Gebski V and Townsend A: Right or left primary site of colorectal cancer: Outcomes from the molecular analysis of the AGITG MAX trial. Clin Colorectal Cancer 18: 141-148, 2018.

24. Ulanja MB, Rishi M, Beutler BD, Sharma M, Patterson DR, Gullapalli N and Ambika S: Colon cancer sidedness, presentation and survival at different stages. J Oncol 2019: 4315032, 2019.

25. Imamura Y, Morikawa T, Liao X, Lochhead P, Kuchiba A, Yamauchi M, Qian ZR, Nishihara R, Meyerhardt JA, Haigis KM, et al: Specific mutations in KRAS codons 12 and 13 , and patient prognosis in 1075 BRAF wild-type colorectal cancers. Clin Cancer Res 18: 4753-4763, 2012.

26. Rasmy A, Fayed A, Omar A and Fahmy N: Effect of KRAS mutational status on disease behavior and treatment outcome in patients with metastatic colorectal cáncer: Intratumor heterogeneity and mutational status. J GastrointestOncol 10: 886-895, 2019.

This work is licensed under a Creative Commons Attribution-NonCommercial-NoDerivatives 4.0 International (CC BY-NC-ND 4.0) License. 